- RAM, REV. ADM. MACKENZIE, V. 12, N. 3, Edição Especial • SÃO PAULO, SP • MAIO/JUN. 2011 • ISSN 1678-6971 • Submissão: 17 jan. 2011. Aceitação: 18 mar. 2011. Sistema de avaliação: às cegas dupla (double blind review). UNIVERSIDADE PRESBITERIANA MACKENZIE. Walter Bataglia (Ed.), p. 51-82.

\title{
DESENVOLVIMENTO SUSTENTÁVEL E EDUCAÇÃO AMBIENTAL: UMA TRAJETÓRIA COMUM COM MUITOS DESAFIOS
}

\section{JOSÉ CARLOS BARBIERI}

Doutor em Administração pela Escola de Administração de Empresas de São Paulo da Fundação Getulio Vargas (FGV-SP).

Professor da Escola de Administração de Empresas de São Paulo da Fundação Getulio Vargas.

Rua Itapeva, 474, $8^{\circ}$ andar, Bela Vista, São Paulo - SP - Brasil - CEP 01332-000 E-mail: jose.barbieri@fgv.br

\section{DIRCEU DA SILVA}

Doutor em Educação pela Faculdade de Educação da Universidade de São Paulo (Feusp).

Professor da Faculdade de Administração de Empresas da Universidade Nove de Julho (Uninove). Avenida Francisco Matarazzo, 612, $2^{\circ}$ andar, Água Branca, São Paulo - SP - Brasil - CEP 05001-000

E-mail: dirceuds@gmail.com 


\section{RESUMO}

O objetivo geral deste artigo é a apresentação do surgimento de uma concepção de educação ambiental (EA) associada ao movimento do desenvolvimento sustentável e uma proposta de educação para o desenvolvimento sustentável (EDS), tendo em vista sua aplicação em cursos de Administração de Empresas, pois, como será mostrado, na concepção dessa EA, deu-se especial atenção aos profissionais cujas atividades e decisões geram repercussões significativas sobre o meio ambiente, como administradores, economistas, engenheiros, arquitetos, desenvolvedores de produtos, formuladores de políticas públicas, entre outros. Serão apresentados os principais eventos intergovernamentais que deram surgimento a essa concepção de EA, as principais diretrizes e recomendações aplicadas a esses profissionais e uma proposta de EDS e sua relação com a EA. Depois, será apresentado um debate sobre a EA e a EDS, pois há entendimentos diametralmente opostos sobre essas duas concepções de educação. Serão apresentados diferentes entendimentos do conceito de desenvolvimento sustentável e as questões polêmicas que geram dúvidas e objeções sobre ele, na perspectiva de dirimir mitos e concepções ingênuas. Também serão abordadas as questões relativas ao crescimento econômico e sua relação com o desenvolvimento, uma das principais questões polêmicas em torno do conceito de desenvolvimento sustentável. O artigo discute conceitos e recomendações constantes nos documentos intergovernamentais, sobretudo os produzidos pelas agências da ONU, que criaram marcos para o debate e introduziram elementos para que se desencadeassem ações mundiais de EA. Por fim, apresentam-se algumas das principais iniciativas voluntárias para a inserção das instituições de ensino superior no movimento do desenvolvimento sustentável, tal como a Declaração de Talloires, para implantar a EA e a EDS.

\section{PALAVRAS-CHAVE}

Educação ambiental; Educação para a sustentabilidade; Desenvolvimento sustentável; Meio ambiente; Ensino de Administração. 


\section{INTRODUÇÃO}

Este artigo tem com objetivo geral a apresentação da gênese de uma concepção de educação ambiental (EA) associada ao conceito de desenvolvimento sustentável e um debate importante que surgiu ao longo de sua trajetória, com a proposta de educação para o desenvolvimento sustentável (EDS).

Essa concepção de EA é um componente essencial do movimento pelo desenvolvimento sustentável que ganhou popularidade, em escala mundial, desde a última década do século passado e cresce a cada dia, à medida que as crises sociais e ambientais de dimensão planetária continuam ameaçando o futuro da humanidade e do próprio planeta. Sua influência na formulação de políticas de EA por diversos países é amplamente conhecida. No Brasil, por exemplo, muito do que dispõe a legislação sobre essa matéria encontra-se nela ou foi nela inspirada.

Essa concepção de EA deu especial atenção aos profissionais cujas atividades e decisões geram repercussões significativas sobre o meio ambiente, como administradores, engenheiros, economistas, desenvolvedores de produtos, formuladores de políticas públicas, entre outros. Assim, inicialmente, serão apresentados os principais eventos intergovernamentais que originaram essa concepção de EA, ressaltando seus objetivos, as principais diretrizes e recomendações de caráter geral, e as especialmente endereçadas a esses profissionais. Depois será apresentada a proposta de EDS e o debate sobre sua relação com a EA.

Como será visto, há diversos entendimentos sobre essas duas concepções de educação; alguns diametralmente opostos. Neste artigo, defende-se a ideia de que, embora sejam concepções diferentes, elas se complementam. Como esse debate está ligado ao conceito de desenvolvimento sustentável, o texto segue discutindo algumas questões polêmicas que geram dúvidas e objeções, como as questões relativas ao crescimento econômico. Por fim, apontam-se algumas iniciativas voluntárias para a inserção das instituições de ensino superior no movimento do desenvolvimento sustentável, para implantar a EA e a EDS.

\section{CONSTRUINDO CONSENSO SOBRE A EA ASSOCIADA AO DESENVOLVIMENTO SUSTENTÁVEL}

Muitos conceitos, objetivos, diretrizes, metodologias e outras questões sobre a EA, associada ao desenvolvimento sustentável, foram concebidos ou desenvolvidos em diversas conferências internacionais, regionais e nacionais sobre meio ambiente, muitas delas tendo a Unesco como promotora ou apoiadora. 
As origens dessa EA estão ligadas à própria criação da Unesco, em I946, órgão da ONU que iniciou o debate em torno da educação de um modo geral e da EA em particular, em termos globais e por meio da mobilização de governos e entidades da sociedade civil. A criação desse órgão faz parte das iniciativas do imediato pós-guerra para construir condições sociais e econômicas que garantissem a paz de forma duradoura.

Em uma de suas iniciativas, a Conferência sobre a Biosfera, realizada em Paris, em I968, foi criado o programa Homem e Biosfera (MaB, do inglês Man and the Biosphere), com vistas a ampliar os entendimentos da relação entre os humanos e o meio ambiente, e promover o conhecimento, a prática e os valores humanos para implantar as boas relações entre as populações e o meio ambiente em todo o planeta.

Essa conferência pode ser considerada o marco inicial do movimento pelo desenvolvimento sustentável. Mesmo depois que outros órgãos da ONU assumiram os debates, como a Assembleia Geral da ONU (ig66) e o Programa das Nações Unidas para o Meio Ambiente (Pnuma), a Unesco continuou dando sua contribuição para esse movimento nos campos da educação e cultura, suas áreas de atuação específica, como será mostrado mais adiante.

Durante a Conferência das Nações Unidas para o Meio Ambiente Humano (Cnumah), realizada em Estocolmo, em I972, foram criados alguns instrumentos para tratar de problemas sociais e ambientais planetários, como a Declaração sobre o Ambiente Humano, com 26 princípios voltados para orientar a construção de ambiente que harmonize os aspectos humanos e naturais, considerados essenciais para o bem-estar dos humanos e para que possam gozar de todos os direitos fundamentais.

De acordo com um desses princípios, é indispensável um trabalho de educação em questões ambientais, dirigido para jovens e adultos. A Conferência de Estocolmo firmou as bases para um novo entendimento acerca das relações entre o ambiente e o desenvolvimento socioeconômico.

O primeiro princípio dessa Declaração é um exemplo dessa visão que integra questões sociais e ambientais, o que confere sentido para a expressão socioambiental:

O homem tem o direito fundamental à liberdade, à igualdade e ao desfrute de condições de vida adequadas em um meio ambiente de qualidade tal que lhe permita levar uma vida digna e gozar de bem-estar, tendo a solene obrigação de proteger e melhorar o meio ambiente para as gerações presentes e futuras (CNUMAH, I972, Princípio I, p. I). 
Após a Conferência de Estocolmo de I972, a EA passou a receber atenção especial em praticamente todos os fóruns relacionados com a temática do desenvolvimento e do meio ambiente. Dela resultou a criação do Programa das Nações Unidas para o Meio Ambiente (Pnuma), que viria a dividir com a Unesco as questões relativas à EA no âmbito das Nações Unidas.

Foi estabelecido um plano de trabalho com iıo resoluções, e uma delas se refere à necessidade de implantar a EA de caráter interdisciplinar com o objetivo de preparar o ser humano para viver em harmonia com o meio ambiente (Resolução n 96). Para cumprir essa resolução, a Unesco e o Pnuma criaram o Programa Internacional de Educação Ambiental (Piea), com o objetivo de promover o intercâmbio de ideias, informações e experiências em EA entre as nações de todo o mundo, fomentar o desenvolvimento de atividades de pesquisa que melhorem a compreensão e a implantação da EA, promover o desenvolvimento e a avaliação de materiais didáticos, currículos, programas e instrumentos de ensino, favorecer o treinamento de pessoal para o desenvolvimento da EA e dar assistência aos Estados membros com relação à implantação de políticas e programas de EA.

Uma das primeiras atividades do Piea foi a realização de um Seminário Internacional sobre Educação Ambiental em I975, no qual foi aprovada a Carta de Belgrado, um importante documento sobre diversas questões pertinentes à EA, sob a perspectiva do desenvolvimento sustentável, embora, nessa época, ainda não se usasse essa expressão, a não ser em círculos muito restritos.

A Carta de Belgrado estabeleceu que a meta básica da ação ambiental seria melhorar todas as relações ecológicas, incluindo as relações do ser humano entre si e com os demais elementos da natureza, bem como desenvolver uma população mundial consciente e preocupada com o meio ambiente e com os problemas associados a ele, com conhecimento, habilidade, motivação, atitude e compromisso para atuar de forma individual e coletiva na busca por soluções para os problemas atuais e para a prevenção de novos problemas.

O público em geral, o principal alvo da EA, é constituído por todos os integrantes da educação formal e não formal. Os primeiros compreendem os alunos e professores de todos os níveis, da pré-escola ao ensino superior e o treinamento profissional; os segundos incluem jovens e adultos, individualmente considerados ou em grupos, de todos os segmentos da sociedade: trabalhadores, administradores, profissionais liberais, entre outros.

Os objetivos da educação ambiental, de acordo com a Carta de Belgrado, são os seguintes:

I. Conscientização: contribuir para que indivíduos e grupos adquiram consciência e sensibilidade em relação ao meio ambiente como um todo e quanto aos problemas relacionados com ele. 
2. Conhecimento: propiciar uma compreensão básica sobre o meio ambiente, principalmente quanto às influências do ser humano e de suas atividades.

3. Atitudes: propiciar a aquisição de valores e motivação para induzir uma participação ativa na proteção ao meio ambiente e na resolução dos problemas ambientais.

4. Habilidades: proporcionar condições para que os indivíduos e grupos sociais adquiram as habilidades necessárias a essa participação ativa.

5. Capacidade de avaliação: estimular a avaliação das providências efetivamente tomadas em relação ao meio ambiente e aos programas de educação ambiental.

6. Participação: contribuir para que os indivíduos e grupos desenvolvam o senso de responsabilidade e de urgência com relação às questões ambientais.

A falta de proposições concretas e uma visão pouco realística foram as críticas mais frequentes à Carta de Belgrado. Apesar disso, ela é um dos documentos mais importantes sobre EA em termos de conceitos, princípios e diretrizes associados ao desenvolvimento sustentável. Muitos de seus termos foram ratificados pela Conferência Intergovernamental sobre EA de Tbilisi, na Geórgia, de I977, na qual foram enunciadas 4I recomendações sobre EA.

A Recomendação $n^{\circ} .8$ especifica três setores da população aos quais a EA deve ser endereçada, a saber: I. a educação do público em geral; 2. a educação de grupos profissionais ou sociais específicos, cujas atividades e influência tenham repercussões sobre o meio ambiente, como engenheiros, administradores, arquitetos, projetistas industriais, formuladores de políticas e agricultores; e 3. a formação de determinados grupos de profissionais e cientistas que se ocupam de problemas ambientais específicos, por exemplo, biólogos, geólogos, toxicólogos, agrônomos, sanitaristas, meteorologistas etc.

A Recomendação $n^{\circ}$. Io é endereçada à formação de profissionais do segundo grupo, mencionado anteriormente, considerando que suas atividades repercutem de maneira importante, direta ou indiretamente, no meio ambiente, mesmo quando não exercidas exclusivamente na esfera do planejamento e da gestão ambiental.

A Declaração de Tbilisi recomenda um programa comum interdisciplinar de estudos ambientais vinculados tanto ao ambiente natural como ao urbano e que estejam relacionados com essas profissões. Recomenda também uma atenção especial quando da elaboração de metodologias e de mecanismos institucionais para atender a esse objetivo.

A Recomendação $n^{\circ}$. II estabelece para esses profissionais dois programas diferentes de EA, a saber: I. programas aprofundados de formação complementar e de formação prática ou programas de formação permanente que lhes permitam estabelecer relações mais adequadas sobre uma base interdisciplinar, cuja metodologia exigirá estudos mais aprofundados, assim como o estabelecimento 
de mecanismos institucionais adequados; e 2. programas pós-universitários destinados a pessoal já especializado em algumas disciplinas.

O método de formação eficaz, segundo a Recomendação n. II, é o que adota um enfoque pluridisciplinar, centralizado na solução dos problemas e no sistema de equipes multidisciplinares integradas, permitindo a formação de especialistas que, depois de adquirirem uma formação interdisciplinar, acrescentarão às suas próprias capacidades a aptidão para atuarem como membros de equipes multidisciplinares.

\section{- capítulo 36 da Agenda 21}

A partir da publicação do relatório Nosso futuro comum, produzido pela Comissão Mundial sobre Meio Ambiente e Desenvolvimento (Cmmad), a expressão desenvolvimento sustentável passou a ser difundida e tornou-se popular, com a Conferência das Nações Unidas para o Desenvolvimento e Meio Ambiente (Cnumad), realizada no Rio de Janeiro, em I992.

Os trabalhos da Cmmad constituem fontes fundamentais dos conceitos e das propostas relacionados com o desenvolvimento sustentável, que serão discutidos mais adiante. Nesse relatório se encontra a definição mais conhecida de desenvolvimento sustentável: "é aquele que atende às necessidades do presente sem comprometer a possibilidade das gerações futuras de atenderem as suas próprias necessidades" (COMISSÃO MUNDIAL SOBRE MEIO AMBIENTE E DESENVOLVIMENTO, I99I, p. 46).

O relatório dedica especial atenção à educação em geral e à EA em especial como meios para alcançar o desenvolvimento sustentável, pois a compreensão dos processos ambientais e de desenvolvimento da maioria das pessoas se fundamenta em crenças tradicionais e em informações transmitidas pela educação convencional (COMISSÃO MUNDIAL SOBRE MEIO AMBIENTE E DESENVOLVIMENTO, I99I, p. I22-I25).

A Agenda 2I, documento aprovado durante a Conferência do Rio de Janeiro, é um programa de ação abrangente para guiar a humanidade em direção a um desenvolvimento que seja ao mesmo tempo socialmente justo e ambientalmente sustentável. Ela é constituída por 40 capítulos, dedicados: I. às diversas questões sociais e ambientais de caráter planetário (erradicação da pobreza, proteção da atmosfera, conservação da biodiversidade etc.); 2. ao fortalecimento dos principais grupos de parceiros para implantar as ações recomendadas (ONGs, governos locais, comunidade científica e tecnológica, sindicatos, indústria e comércio etc.); e 3. aos meios de implementação, como mecanismos financeiros, desenvolvimento científico e tecnológico, cooperação internacional e a promoção do ensino. 
A promoção do ensino está presente em praticamente todas as áreas e os programas da Agenda 2I. Além disso, o Capítulo 36 é inteiramente dedicado à promoção do ensino, da conscientização pública e do treinamento. Embora conste em seu preâmbulo que as recomendações da Conferência de Tbilisi ofereceram os princípios fundamentais desse capítulo, uma análise de seu texto mostra que ele foi muito mais influenciado pela Conferência Mundial do Ensino para Todos para a Satisfação das Necessidades Básicas de Aprendizado, realizada em Jomtien, Indonésia, em I990.

Com efeito, apenas uma única menção foi feita à EA em todo o texto do Capítulo 36. Esse fato mostra uma mudança de trajetória no âmbito das conferências intergovernamentais promovidas pela ONU e nos documentos produzidos por elas.

A Declaração de Jomtien reafirma a ideia da educação como um direito fundamental de todos, mulheres e homens, de todas as idades, no mundo inteiro, e que pode contribuir para conquistar um mundo mais seguro, mais sadio, mais próspero e ambientalmente mais puro, ao mesmo tempo que favoreça o progresso social, econômico e cultural, a tolerância e a cooperação internacional.

A Declaração reconhece que uma educação básica adequada é fundamental para fortalecer os níveis superiores de ensino, a formação científica e tecnológica e, por conseguinte, para alcançar um desenvolvimento autônomo. A educação básica é considerada, de modo amplo, como satisfação das necessidades de aprendizagem ao longo de toda a vida para todos (UNESCO, I990).

O Capítulo 36 da Agenda 2I apresenta três áreas de programas: I. reorientação do ensino no sentido do desenvolvimento sustentável; 2. aumento da consciência pública; e 3. promoção do treinamento. Com relação à primeira, tanto no ensino formal quanto no informal, a reorientação para o desenvolvimento sustentável é considerada indispensável para modificar a atitude das pessoas e para conferir consciência ambiental, ética, valores, técnicas e comportamentos em consonância com as exigências de um novo padrão de responsabilidade socioambiental. Para se tornar eficaz, o ensino sobre o meio ambiente e o desenvolvimento deve considerar a dinâmica do desenvolvimento do meio físico, biológico e social, estar integrado em todas as disciplinas e empregar métodos formais e informais e meios efetivos de comunicação. Uma das diversas atividades dessa área de programa é especialmente endereçada às empresas e às escolas de comércio, indústria e agricultura para que incluam temas relacionados com o desenvolvimento sustentável em seus programas de ensino e treinamento (CONFERÊNCIA DAS NAÇÕES UNIDAS SOBRE MEIO AMBIENTE E DESENVOLVIMENTO, I992, seções 36.3 a 36.5 ).

O aumento da consciência pública, outra área de programa, tem por objetivo sensibilizar e conscientizar o público, amplamente considerado, sobre os proble- 
mas do meio ambiente e do desenvolvimento, a fim de fomentar nos indivíduos o senso de responsabilidade com relação a esses problemas e fazer com que participem da busca por solução (CONFERÊNCIA DAS NAÇÕES UNIDAS SOBRE MEIO AMBIENTE E DESENVOLVIMENTO, I992, seções 36.8-II).

A terceira área de programa se refere à promoção do treinamento e é dirigida a profissões determinadas para preencher lacunas em seus conhecimentos e suas habilidades, com vistas a encontrar empregos e participar de atividades concernentes ao meio ambiente e ao desenvolvimento, ao mesmo tempo que reforçam ou ampliam sua conscientização em relação aos temas de seus programas de aprendizado. Visa, entre outros objetivos, garantir que considerações ambientais e de ecologia humana sejam integradas em todos os níveis administrativos e áreas funcionais, tais como marketing, produção e finanças (CONFERÊNCIA DAS NAÇÕES UNIDAS SOBRE MEIO AMBIENTE E DESENVOLVIMENTO, I992, seções 36.I3).

A Agenda recomenda que as associações profissionais devem revisar seus códigos de ética e conduta para incluir um compromisso mais forte com as dimensões ambientais e sociais do desenvolvimento. Os governos, a indústria, os sindicatos e os consumidores devem promover o aprofundamento da compreensão da relação existente entre um meio ambiente saudável e práticas empresariais saudáveis (CONFERÊNCIA DAS NAÇÕES UNIDAS SOBRE MEIO AMBIENTE E DESENVOLVIMENTO, I992, seções 36.15 e 20).

A Comissão de Desenvolvimento Sustentável (CDS) foi criada em I992 para acompanhar e avaliar a implantação das áreas de programas e atividades recomendadas pela Agenda 2I e a cooperação internacional relacionada com elas. A coordenação das atividades do Capítulo 36 da Agenda ficou a cargo da Unesco, que promoveu uma iniciativa internacional denominada Educação para o Futuro Sustentável (EPS), em I994, com o propósito de reforçar os objetivos, as propostas e as recomendações constantes nesse capítulo e nas conferências mencionadas.

Em I996, com base em uma avaliação sobre o progresso geral alcançado pelas áreas de programas do Capítulo 36 da Agenda 2I, a CDS, após reafirmar a importância da educação como a pedra angular do desenvolvimento sustentável, propôs novas prioridades constantes em três objetivos fundamentais: I. reorientar a educação básica para o desenvolvimento sustentável, por meio de uma reforma do ensino em seu conjunto, e não apenas por meio de modificações nos planos de estudos vigentes ou pela adição de novos componentes; 2. aumentar a consciência do público, uma vez que o apoio e a participação da população é um fator cada vez mais importante para as mudanças que esse tipo de desenvolvimento requer; e 3. fomentar capacitação para que se possa contar com os recursos humanos necessários para planejar e aplicar o desenvolvimento sustentável nos diversos setores da atividade humana (COMISIÓN SOBRE DESARROLLO SOSTENIBLE, I997, p. 2). 
Essa mudança de prioridade modificaria a atuação da Unesco e do Pnuma em relação à EA. Tal mudança foi precedida pelo encerramento, em I995, das atividades do Piea, que havia sido criado como resultado da Conferência de Estocolmo, como já mencionado. Em I997, a Assembleia Geral da ONU, com base nessa avaliação da CDS, adotou um programa para implantar a Agenda 2I, na qual os temas do Capítulo 36 passaram a ter as prioridades citadas.

Esse programa usa as expressões educação para a sustentabilidade e educação para o futuro sustentável, cujos temas centrais incluem, entre outros, a educação permanente, a educação interdisciplinar e a educação multicultural. As parcerias são colocadas como essenciais para a consecução desse programa e devem envolver uma diversidade de agentes, tais como escolas de todos os níveis, governos, ONGs, empresas, organizações profissionais, educadores etc. À Unesco é confiada a tarefa de desenvolver esse novo conceito de educação (ASAMBLEA GENERAL DE LAS NACIONES UNIDAS, I997).

\section{EDUCAÇÃO PARA O DESENVOLVIMENTO SUSTEN'TÁVEL}

Foi dentro desse quadro de mudanças que se realizou, em I997, a Conferência Internacional sobre Meio Ambiente e Sociedade, em Tessalônica, Grécia. Essa conferência marcou uma mudança profunda na trajetória da EA, no âmbito da Unesco, nem sempre bem-vista por praticantes da EA, como será mostrado oportunamente.

A Declaração de Tessalônica considerou válidos os planos e as recomendações das conferências de Belgrado, Tbilisi, Moscou e outras relacionadas com a $\mathrm{EA}$, mas reconheceu que não foram completamente explorados, e os resultados alcançados foram insuficientes. A educação é expressamente colocada como um instrumento privilegiado para alcançar o desenvolvimento sustentável (UNESCO, 1997).

Com efeito, a Declaração de Tessalônica afirma que a educação e a consciência pública adequadas constituem pilares da sustentabilidade cujo conceito envolve, além do meio ambiente, a pobreza, a população, a saúde, a segurança alimentar, a democracia, os direitos humanos e a paz. Reconhece que a EA desenvolvida segundo as recomendações de Tiblisi e sua evolução posterior contemplam uma vasta gama de temas globais incluídos nas conferências da ONU e na Agenda 2I, por isso também tem sido tratada como educação para a sustentabilidade, podendo referir-se a ela como educação para o meio ambiente e a sustentabilidade.

Reafirma a ideia de que o conceito de sustentabilidade não envolve apenas o meio ambiente, mas também questões como pobreza, população, saúde, segu- 
rança alimentar, democracia, direitos humanos e paz. Reafirma também que a sustentabilidade deve ser tratada com enfoque holístico, interdisciplinar, considerando os contextos locais, regionais e nacionais particulares (UNESCO, I997).

A Declaração de Tessalônica recomenda que os planos de ação para a educação, o meio ambiente e a sustentabilidade sejam elaborados em nível local e regional e que a educação faça parte integral das Agendas 2I locais. Recomenda que as escolas sejam estimuladas e apoiadas no sentido de adequarem seus currículos para atender às necessidades de futuro sustentável. Recomenda fortalecer e reorientar os programas de formação de professores e identificar e intercambiar práticas inovadoras e que a comunidade científica desempenhe um papel ativo para assegurar que o conteúdo da educação e os programas de conscientização pública sejam fundamentados em informação atualizada (UNESCO, I997).

Lamentavelmente, ela traz uma nota destoante quando diz que a pobreza gera crescimento da população e degradação ambiental, embora acerte ao reafirmar que a redução da pobreza constitui uma meta essencial e uma condição indispensável para a sustentabilidade.

Não falta quem considere a pobreza como fator de degradação ambiental. O Banco Mundial (WORLD BANK, I992, p. 67), um importante formador de opinião entre tomadores de decisão, manifestou mais de uma vez essa opinião, por exemplo, quando afirmou que as famílias pobres, para atenderem às suas necessidades de curto prazo, arruínam o capital natural, cortando mais árvores do que conseguem repor. Trata-se de um pensamento falacioso, pois essas famílias estão apenas se defendendo como podem e agem assim por falta de melhores opções. Sabe-se, no entanto, que a principal causa da degradação está associada ao consumo exacerbado dos segmentos afluentes das sociedades.

Dez anos depois da Conferência do Rio de Janeiro, foi realizada a Cúpula Mundial sobre Desenvolvimento Sustentável (CMDS), em Johannesburgo, em 2002, conhecida como Rio+10, com o objetivo de tratar de cinco temas específicos definidos pelo secretário-geral das Nações Unidas, na época Kofi Annam: água e saneamento, energia, saúde, agricultura, biodiversidade e gestão de ecossistemas. Porém, outros temas acabaram sendo considerados, como a pobreza, a globalização e os problemas da África. Ao final, elaborou-se um plano de implantação, contendo I53 recomendações para o efetivo cumprimento da Agenda 2I e os princípios constantes na Declaração do Rio de Janeiro sobre Meio Ambiente e Desenvolvimento. Diversas recomendações relacionadas com a educação foram contempladas nesse plano, mas de modo geral, e não especialmente sobre EA.

Por exemplo, as Recomendações iıo e iız do Plano de Ação da CMDS se referem ao provimento de recursos para cumprir as metas de universalização do ensino. A Recomendação iıı é voltada para enfrentar os efeitos da Aids sobre os sistemas de educação nos países gravemente afetados por essa pandemia. A Recomendação II3 trata da erradicação das disparidades entre gêneros no ensino 
primário e secundário, conforme estabelecido na Conferência de Dacar. A Recomendação II4 reafirma a necessidade de integrar o desenvolvimento sustentável nos sistemas de ensino, em todos os níveis educativos, a fim de promover o papel da educação como agente-chave de mudança. A Recomendação II7 se refere à necessidade de apoiar o uso da educação para promover o desenvolvimento sustentável, inclusive por meio de ações de caráter urgente, entre elas, recomendar à Assembleia das Nações Unidas que proclame um decênio para a educação quanto ao desenvolvimento sustentável (CMDS, 2002).

Em 2003, a Assembleia Geral das Nações Unidas acatou essa recomendação e, reconhecendo que a educação é indispensável ao desenvolvimento sustentável, proclamou o Decênio das Nações Unidas da Educação para o Desenvolvimento Sustentável (Dnueds), designando à Unesco a responsabilidade por sua promoção. O objetivo desse Decênio, que vai de 2005 a 20I4, é a promoção do ensino e da aprendizagem para todos, ao longo de toda a vida, como parte do processo para alcançar o desenvolvimento sustentável, conforme os documentos produzidos em Jomtien e Dacar.

O Dnueds se refere a um projeto de dimensão planetária que objetiva atender às necessidades básicas do presente, sem prejudicar a capacidade de as gerações futuras atenderem às suas necessidades, conforme a definição da Cmmad, comentada anteriormente, enquanto a educação para o desenvolvimento sustentável (EDS) tem por objetivo o provimento de conhecimentos e de atitudes para que as pessoas possam tomar decisões e agir de forma coerente com os propósitos e, desse modo, conceber o desenvolvimento. Em outras palavras, a EDS é um instrumento do desenvolvimento sustentável, da mesma forma que a EA foi considerada nos documentos das conferências citadas.

O Dnueds objetiva intensificar os esforços para incorporar princípios, valores e recomendações concernentes ao desenvolvimento sustentável, em todos os aspectos da educação e da aprendizagem (ASAMBLEA GENERAL DE LAS NACIONES UNIDAS, 2002).

Educação para a sustentabilidade, educação para um futuro sustentável, educação para o desenvolvimento sustentável passaram a ser expressões usadas como sinônimas nos documentos da ONU e da Unesco a partir de então. Como diz um documento da Unesco de I997, as raízes de uma educação para o desenvolvimento sustentável estão firmemente implantadas na EA, que, em sua breve trajetória, se esforçou para alcançar metas e resultados similares aos inerentes ao conceito de desenvolvimento sustentável, e compreendem um amplo espectro de dimensões ambientais, sociais, éticas, econômicas e culturais. Esse documento dá a entender que a EDS é uma evolução da EA.

Ainda segundo o documento da Unesco (I997, p. 3I-32), muitas recomendações da Conferência do Rio de Janeiro de I992 são ecos de Tbilisi, tais como: 
- $\quad$ O entendimento de que a meta da EA é conseguir que as pessoas e as comunidades compreendam o caráter complexo do meio ambiente natural e artificial, resultante da interação de seus aspectos físicos, biológicos, sociais, econômicos e culturais, bem como adquirir conhecimento, valores, atitudes e aptidão prática que permitam participar de forma responsável e eficaz no esforço de prever e resolver problemas ambientais.

- Outro objetivo básico da EA consiste em evidenciar a interdependência econômica, política, ecológica do mundo moderno e que as atividades de diferentes países podem provocar repercussões internacionais.

- Deve-se prestar atenção especial ao objetivo de compreender as complicadas relações entre o desenvolvimento socioeconômico e o melhoramento do meio ambiente.

Nesses e em outros documentos da Unesco posteriores à Tessalônica, a educação para o desenvolvimento sustentável (EDS) é uma proposta ambiciosa para reformular completamente a educação em escala global, alinhada com os objetivos das conferências da ONU desencadeadas em Estocolmo, em I972, relacionadas com meio ambiente e desenvolvimento, e a Conferência de Jomtien, de I990, e o Fórum Mundial sobre Educação de Dacar.

Com relação à EA, esses documentos permitem interpretações variadas. A Declaração de Tessalônica, na única vez que menciona a EA, considera que ela, desenvolvida segundo as recomendações de Tiblisi e seus desdobramentos posteriores, por contemplar uma vasta gama de temas globais incluídos nas conferências da ONU e na Agenda 2I, também tem sido tratada como educação para a sustentabilidade. Essa frase permite interpretar que não há diferença entre ambas ou que a EA foi se transformando na EDS.

Porém, há outras interpretações. Por exemplo, Sauvé (2005) considera a EA desenvolvida pelo Piea, que vigorou de I972 a I995, como uma corrente específica denominada resolução de problemas e distinta da corrente do desenvolvimento sustentável. Uma pesquisa realizada entre junho de I999 e março de 2000 , com 50 participantes de 25 países, a maioria com experiência ou formação acadêmica em EA, mostrou uma variedade de opiniões sobre EA e EDS, como exemplificado a seguir:

- A EDS difere significativamente da EA de caráter naturalista, apolítica e científica praticada nos anos I980 e início da década de I990.

- A EA é um componente essencial da EDS, entre muitos outros componentes, tais como sistemas dinâmicos, sustentabilidade econômica, globalização, educação intercultural, pensamento estratégico, educação fundamentada na comunidade etc. 
- A EA é um componente da EDS e um dos que contribuíram para sua conceituação. Enquanto a EDS se volta para as dimensões sociais, políticas e econômicas, a EA se concentra na dimensão ambiental.

- A EDS provê orientação útil para a EA.

- A EA, diferentemente da EDS, confere atenção quase exclusiva sobre as forças naturais e atenção insuficiente para a necessidade de mudanças profundas nas forças sociais que limitam a habilidade de desenvolver um modo de vida equilibrado com o meio ambiente.

- A EA tem falhado, em grande medida, em iniciar uma discussão com tomadores de decisão dos governos e das empresas, enquanto a EDS procura fazer isso de modo explícito. A EA representa interesses de grupos.

- A EDS tem um foco mais nítido e crítico do que a EA (HASSELINK; KEMPEN; WALS, 2000, p. 5- I3).

As opiniões dos participantes da pesquisa apresentam quatro perspectivas de relação entre EA e EDS, como mostra a Figura I, mas a maioria considerou a EDS como o próximo estágio na evolução da EA ou uma nova geração de EA. De acordo com McKeown (2002, p. 5), as primeiras ideias sobre a EDS estão no Capítulo 36 da Agenda 2I e, diferentemente da maioria dos movimentos educativos, não teve início na comunidade de educadores, mas sim em fóruns políticos e econômicos intergovernamentais, como ONU, Organização para Cooperação e Desenvolvimento (OCDE), Organização dos Estados Americanos etc. O desenvolvimento conceitual da EDS, de forma independente da participação da comunidade de educadores, é um problema reconhecido tanto pelos docentes quanto pelos órgãos internacionais. Essa é com certeza uma das razões pelas quais a EDS é malvista por muitos praticantes da EA.

\section{FIGURA I}

\section{PERSPECTIVAS SOBRE A RELAÇÃO ENTRE EA E EDS}

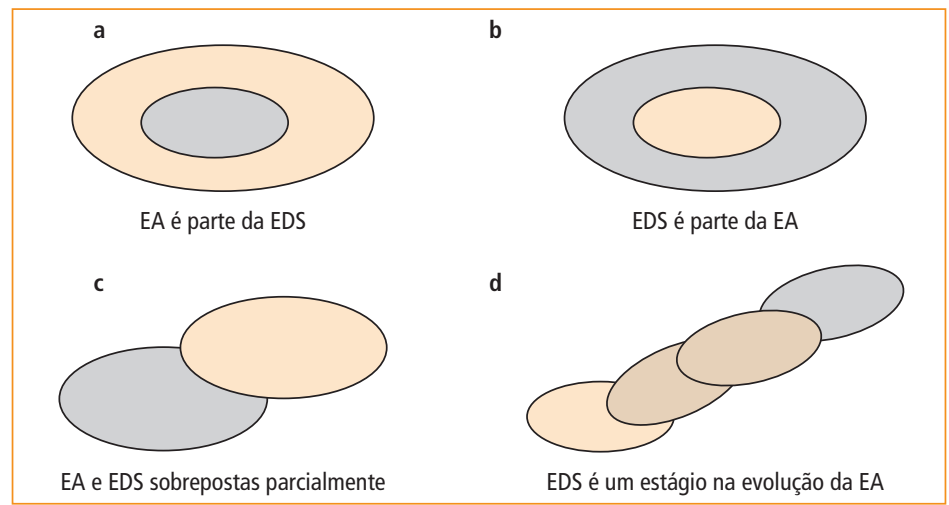

Fonte: Hasselink, Kempen e Wals (2000, p. I2). 
Pesquisas realizadas em 2004 com a comunidade de educadores ambientais do Brasil e de outros países da América Latina e do Caribe também mostram a divergência de entendimento sobre EA e EDS. No Brasil, a pesquisa foi feita com I.740 participantes do V Fórum Brasileiro de Educação Ambiental, realizado em Goiânia, com base no mesmo questionário de uma pesquisa realizada pela Secretaria de Educação Pública do México, enviada por meio eletrônico a Io I especialistas em EA, de I7 países latino-americanos e caribenhos. Da amostra total, $53 \%$ opinaram que não seria conveniente mudar a denominação de EA para EDS, o que foi corroborado por $77 \%$ da amostra brasileira. Dos que consideraram conveniente mudar a denominação, $65 \%$ justificaram que a EDS envolve temas sociais e econômicos, e não apenas ecológicos; $22 \%$ entenderam que a mudança representaria uma evolução natural da EA; e ı०\% mencionaram que a mudança representaria uma tendência internacional, e os apoios financeiros acompanhariam essa tendência.

Da amostra brasileira favorável à mudança, $75 \%$ mencionaram o envolvimento dos temas sociais e ambientais, e $25 \%$, a evolução natural. Quanto aos que não apoiam a mudança, $38 \%$, na pesquisa mexicana, apontaram que, no contexto da região latino-americana e caribenha, a EA já contempla questões sociais e econômicas; $24 \%$ julgaram a EDS confusa conceitual e operacionalmente; e $22 \%$ indicaram que a mudança pode representar a perda de um capital simbólico construído nessa região com enormes dificuldades.

$\mathrm{Na}$ pesquisa brasileira, esse último motivo teve importância menor. Em suma, os respondentes das duas pesquisas entendem que as dimensões sociais e econômicas devem estar presentes na EA, a maioria acha inconveniente a mudança de EA para EDS, e muitos acreditam que a EA já incorpora a dimensão social e econômica, não se atendo às questões ecológicas (BRASIL, 2007, p. 9-19).

De fato, muitas concepções de EA já incorporaram as dimensões econômicas e sociais, de acordo com a perspectiva do desenvolvimento sustentável, de modo que é indiferente falar em EA ou EDS. Esse é o caso da EA, conforme a legislação brasileira (BRASIL, I999). Porém, como há diversas correntes de EA, Sauvé (2005) apresenta quinze, e nem todas consideram essas dimensões. Sob essa perspectiva, denominar EDS pode ser uma forma de sublinhar a especificidade dessa corrente para distingui-la das demais. Entre os que olham com desconfiança a EDS, além dos motivos apontados, estão as muitas críticas feitas aos diferentes entendimentos sobre desenvolvimento sustentável, como será mostrado a seguir. 


\section{CRÍTICAS E OBJEÇõES AS DESENVOLVIMENTTO SUSTENTÁVEL}

A expressão "desenvolvimento sustentável" se tornou popular após a Conferência das Nações Unidas sobre Meio Ambiente e Desenvolvimento, realizada no Rio de Janeiro, em I992, embora já estivesse presente, com diferentes denominações, desde a Conferência de Estocolmo, de 1972.

A definição de desenvolvimento sustentável da Comissão Brundtand, de I987, passou a ser citada em praticamente todos os documentos oficiais da ONU e suas agências, como a Unesco, Pnuma, Pnud, Unido e Unctad, em documentos oficiais de entidades intergovernamentais, como OMC, OMS e Banco Mundial, em leis nacionais e subnacionais, em documentos de empresas e ONGs, e já faz parte do repertório de pessoas mais esclarecidas do público em geral. Hoje, é crescente o número de empresas que a colocam em suas missões e declarações. A adesão foi tanta e tão rápida que não é exagero afirmar que se trata de verdadeiro sucesso em termos de popularidade. Mas também não são poucos os que se manifestaram contrários à ideia de desenvolvimento sustentável.

Uma fonte de críticas advém da palavra desenvolvimento, que evoca outra, crescimento. Esse fato não é de pouca monta, pois desenvolvimento e crescimento são considerados, em muitos casos, como sinônimos na linguagem corrente. Um sentido mais específico de desenvolvimento é movimento em direção ao melhor, segundo Abbagnano (2007, p. 284). Esse autor entende que esse sentido tem precedente no conceito aristotélico de movimento como passagem da potência ao ato e que seu significado mais otimista é peculiar à filosofia do século XIX, estreitamente ligado ao conceito de progresso.

Como diz Villeneuve (I998, p. 43-44), a noção de desenvolvimento responde a uma aspiração do ser humano, e, assim como qualquer pessoa deseja realizar seu potencial do ponto de vista físico e intelectual, as sociedades procuram, em sua evolução, desenvolver seus planos econômicos e culturais. No âmbito da economia e das políticas econômicas, desenvolvimento significa mudanças para melhorar o padrão de vida da população de um país, uma região ou um local, decorrentes de mudanças econômicas, por exemplo, no aumento da participação das atividades de manufatura e de serviço na composição do Produto Nacional Bruto (PNB), no aumento da oferta de energia e de vias de transporte, entre outras.

No Relatório da Comissão Mundial sobre Meio Ambiente e Desenvolvimento - Cmmad (I99I, p. 53 e 56), um dos principais veículos de irradiação das ideias concernentes ao desenvolvimento sustentável, o crescimento também veio associado ao desenvolvimento. Com efeito, o crescimento é entendido como condição necessária para erradicar a pobreza. 
A Cmmad exorta os países a retomar o crescimento econômico, sejam eles desenvolvidos ou não. O crescimento é entendido como aumento da riqueza de um país, uma região ou um local, enquanto desenvolvimento é concebido como mudança da qualidade de vida de suas populações. Mas há a ressalva de que também é necessário mudar a qualidade do crescimento para torná-lo mais justo, equitativo e menos intensivo em materiais e energia.

A retomada do crescimento com um objetivo do desenvolvimento sustentável tanto suscita críticas e desconfianças por diversas razões quanto aplausos e regozijos. Entre os críticos está Daly (I99I) que, ao contrário da retomada do crescimento, defende a necessidade de limitar as atividades humanas à capacidade de suporte do planeta, bem como o nível da população e o padrão médio de consumo per capita de recursos naturais. No entanto, foi a menção à retomada do crescimento que trouxe popularidade ao desenvolvimento sustentável entre os políticos profissionais de modo geral, pois o crescimento econômico sempre foi bandeira fácil de carregar e de render votos.

Para os governantes, o crescimento econômico gera impostos e uma gestão mais tranquila, pois aumenta a possibilidade de atender às demandas de diversos setores da sociedade, além do fato de que uma economia em crescimento gera menos greves e necessidades de recursos para atender desempregados. Um político que propõe em sua plataforma reduzir o crescimento econômico certamente teria uma vida política curta.

Na opinião de McNeill (2000, p. 336), o crescimento se tornou um fetiche que contribuiu para gerar um mundo mais populoso e mais estressado. Nem os economistas escaparam de sua atração, pois os que ousaram desafiá-lo foram excluídos de seu círculo até o final do século XX. Conforme esse autor, a prioridade excessiva dada ao crescimento econômico foi certamente a ideia mais importante do século XX.

Quando se incluiu o crescimento como objetivo do desenvolvimento sustentável, obteve-se a adesão crescente dos empresários e seus representantes e de dirigentes de empresas, principalmente das grandes empresas e das multinacionais. É nesse sentido que se entende a desconfiança de muitos, tal como Pedrini (2006), para quem a proposta da Unesco de uma educação vinculada ao desenvolvimento sustentável é dirigida ao capital internacional com ênfase nas regras de mercado.

Como mostra qualquer texto sobre estratégia empresarial, o crescimento é um objetivo estratégico recorrente, cuja validade não se questiona; apenas quanto ao modo de alcançá-lo. Crescer ou morrer é uma máxima que orienta as decisões de dirigentes empresariais, e os cursos de Administração a difundem para os alunos. As práticas administrativas usuais premiam os que promovem o crescimento com bônus, aumento de salário e outros incentivos. Um dirigen- 
te contrário ao crescimento de sua empresa causaria estranheza no ambiente empresarial.

A facilidade com que muitas empresas e entidades empresariais aderiram ao movimento do desenvolvimento sustentável tem gerado ceticismo em muitas correntes ambientalistas, que, por sua vez, são acusadas de atrasadas, regressistas ou utópicas por parte de muitos empresários e suas entidades. Quando empresas fabricantes de cigarros afirmam que contribuem para o desenvolvimento sustentável, porque ajudam os pequenos produtores rurais, ensinando-lhes melhores práticas agrícolas que melhoram a produtividade do cultivo do fumo; quando empresas causadoras de desastres ambientais de grande proporção se dizem sustentáveis porque algumas de suas unidades obtiveram a certificação de seu sistema de gestão ambiental; quando empresas produtoras de armas bélicas se dizem sustentáveis por terem programas de controle da poluição exemplares; ou quando as forças armadas de um país beligerante e destrutivo como a dos Estados Unidos são consideradas sustentáveis por economizar energia e coletar os resíduos que produzem para efeito de reciclagem, percebe-se claramente que o sentido dessa expressão se tornou muito elástico.

De fato, Lélé (I99I, p. 6I) já advertia sobre o uso indiscriminado da expressão desenvolvimento sustentável em uma época em que ainda não havia se tornado popular, como hoje se observa. Depois de comentar sobre as diversas interpretações, como representadas na Figura 2, conclui o autor que desenvolvimento sustentável é um metaobjetivo que une todo o mundo, do industrialista, com sua mente voltada para o lucro, ao agricultor de subsistência, que minimiza os riscos de sua atividade, ao trabalhador e aos programas sociais ligados à busca de equidade com o indivíduo do primeiro mundo, preocupado com a poluição ou com a vida selvagem, bem como o formulador de políticas públicas maximizadoras do crescimento, o burocrata orientado por objetivos e, por conseguinte, o político interessado em votos.

Conforme Porrit (2003, p. III), essa maleabilidade quase infinita que se observa desde que o conceito foi apresentada pela Cmmad, que, em vez de desencadear objeções e reprovações, fez com que pessoas de todas as convicções participassem do debate, dado seu caráter versátil e aberto.

Para O’Riordan (I997, p. I44), o enorme prestígio do desenvolvimento sustentável se alimenta do fato de que as pessoas querem acreditar que é possível alcançá-lo pelo conforto que produz, pois traz a ideia de bem-estar e segurança em um mundo de paz e tolerância cultural. Assim, seria uma espécie de artigo de fé, a exemplo da justiça e da liberdade.

Na opinião de Caldwell (I993, p. I95-196), a razão desse prestígio vem do fato de ser um conceito suficientemente positivo e excessivamente inespecífico, podendo, desse modo, ser um lema do movimento ambientalista internacional ou um clichê. 


\section{FIGURA 2}

\section{DESENVOLVIMENTO SUSTENTÁVEL:}

\section{CONCEITOS, SIGNIFICADOS E INTERPRETAÇÕES}

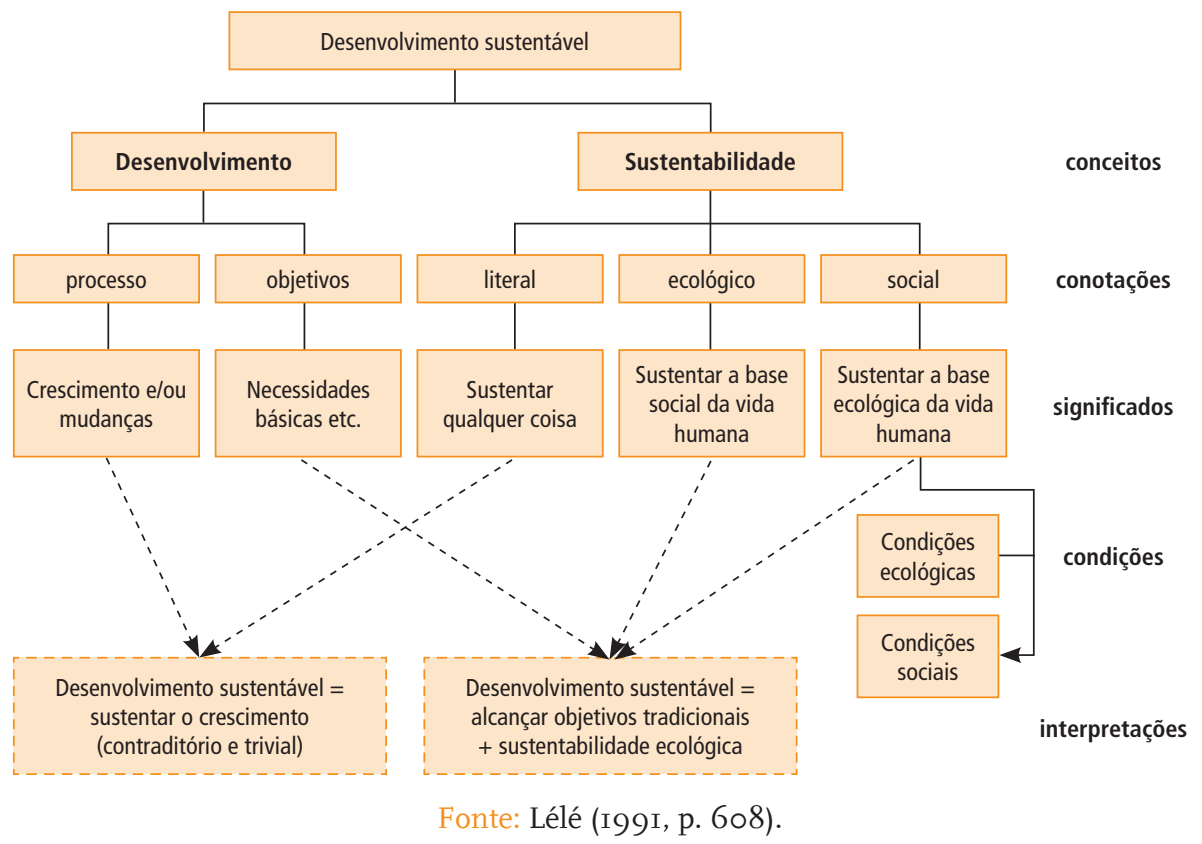

Outra questão que suscita polêmicas e coloca contendores em posições radicalmente antagônicas é o entendimento sobre a palavra sustentável, adjetivo que qualifica esse tipo de desenvolvimento. A dificuldade é tanta que, nos países e nas regiões de língua francesa, se usa a expressão durável (durable), em vez de sustentável, e desenvolvimento durável (développment durable), em vez de desenvolvimento sustentável (VILLENEUVE, I998, p. 55). Também é frequente o uso da palavra sustentabilidade no lugar de desenvolvimento sustentável, principalmente no ambiente das empresas e dos cursos de Administração.

Por exemplo, Elkington (2000, p. 2I), em um livro que se tornou célebre por ter apresentado um famoso modelo de gestão conhecido por Triple Bottom Line, define sustentabilidade como "o princípio que assegura que as ações de hoje não irão limitar a gama de opções econômicas, sociais e ambientais disponíveis para a futura geração".

Savitz e Weber (2006, p. I0) definem sustentabilidade como a "arte de fazer negócios num mundo interdependente” e empresa sustentável como "a que cria lucro para os seus acionistas enquanto protege o meio ambiente e melhora a vida das pessoas com quem interage". 
Esse modo de empregar o termo sustentabilidade e sua associação com a gestão empresarial desperta desconfiança por parte de muitos praticantes da EA, de acordo com os conceitos, os objetivos, as diretrizes e as recomendações constantes nos documentos gerados nas conferências citadas; e com razão, pois são propostas que em essência apenas atualizam as práticas empresariais para ajustá-las às novas demandas por equidade social e respeito ao meio ambiente, sem questionar seus fundamentos e sem abdicar do crescimento como objetivo permanente das empresas.

O uso da palavra sustentabilidade evita o espinhoso debate sobre crescimento e desenvolvimento, um dos principais pontos de discórdia acerca do conceito de desenvolvimento sustentável, bem como evita o debate sobre a natureza política e institucional que o conceito de desenvolvimento sempre trouxe consigo, o que leva necessariamente à inclusão dos governos e de suas instituições na condução dos processos de desenvolvimento.

A substituição da expressão desenvolvimento sustentável pela palavra sustentabilidade não é mera operação linguística. Nessa expressão, desenvolvimento é um substantivo concreto, adjetivado pela palavra sustentável, de modo que o que importa é o desenvolvimento entendido como melhoria da qualidade de vida de todos os humanos, o que significa o provimento de justiça social, obtido de modo que respeite as condições e características do meio ambiente como um legado às futuras gerações para que elas possam prover suas subsistências com qualidade de vida. Sustentabilidade, um substantivo abstrato, já não carrega mais as questões relativas ao desenvolvimento e, entre elas, as ideias de projetos políticos conduzidos pelo interesse público.

A visão centrada na empresa e nos que interagem com ela é encarada por muitos críticos como insuficiente para provocar as mudanças profundas que seriam necessárias para atender às necessidades de todos os humanos desta e das futuras gerações. Como bem observou Sachs (1993, p. 2), a eficiência econômica deve ser avaliada em termos macrossociais, e não apenas do ponto de vista da lucratividade microempresarial.

O debate EA versus EDS se nutre, em grande parte, de críticas como as mencionadas. Está fora do propósito deste trabalho fazer um levantamento mais amplo das críticas. Como diz um documento da Unesco (I997, p. I7-I8), apesar das muitas definições de desenvolvimento sustentável, talvez seja possível compreender melhor seu significado como uma visão nascente, mais do que um conceito definido com nitidez. Sua força reside em reconhecer francamente a interdependência entre as necessidades humanas e as exigências ambientais e, com isso, rechaçar a busca insistente de um só objetivo, em detrimento de outros.

Desenvolvimento sustentável, que pode ser definido sumariamente como um modo de desenvolvimento que não prejudica o desenvolvimento futuro, foi 
concebido, em essência, para funcionar como critérios considerados aceitáveis nos processos de modificação do meio ambiente.

Mesmo que a geração atual não esteja apta para prever as necessidades das gerações futuras, o desenvolvimento futuro necessitará de recursos e da capacidade do meio ambiente de assimilar impactos e regenerar as funções naturais que dão suporte à vida. Portanto, pode-se, razoavelmente, supor que as medidas para minimizar o uso de recursos e as alterações dessas funções são passos corretos na direção desse modo de desenvolvimento. Pode-se supor também como certo que a realização dessas medidas exige uma estrutura social que lhe confere suporte. Não se deve esquecer que uma geração deixa para a outra um pacote constituído não só de custos, mas também de benefícios, tais como conhecimentos tecnológicos e outras formas de capital humano e social, sem os quais os recursos naturais não teriam o valor que têm para os humanos (HOLLAND, 2003, p. 4II).

Do exposto, pode-se dizer que a EDS é um projeto mais amplo para reorientar a educação em escala global e que já estava esboçada no Capítulo 36 da Agenda 2, em suas três áreas programas: reorientar a educação no sentido do desenvolvimento sustentável; aumentar a consciência pública; e promover treinamento para desenvolver recursos humanos para facilitar a transição para um mundo sustentável.

Reorientar a educação é uma expressão-chave para entender essa proposta (HOPKINS; MCKEOWN, 2002, p. I7). As habilidades, os valores e as atitudes requeridos para a EDS não diferem daqueles apresentados na Carta de Belgrado e na Declaração de Tbilisi, relativas à EA, apenas coloca-as em um quadro mais amplo, combinando as propostas de educação para todos, de Jomtien e Dacar, com as de desenvolvimento sustentável.

A Figura 3 ilustra as trajetórias da EA e da EDS construídas no âmbito da ONU e suas entidades e seus órgãos (Unesco, Pnuma, CDS etc.). Ambas possuem raízes comuns próximas aos documentos aprovados nas conferências de Estocolmo e do Rio de Janeiro, de I972 e I992, respectivamente, e raízes mais profundas, como a Declaração Universal dos Direitos do Homem, de I948; o Pacto Internacional sobre os Direitos Civis e Políticos, de I966; o Pacto Internacional dos Direitos Econômicos, Sociais e Culturais, de I966; a Conferência sobre a Biosfera, da Unesco, de I968; a Convenção Internacional sobre a Eliminação de Todas as Formas de Discriminação Racial, de I968; e a Convenção Internacional sobre a Eliminação de Todas as Formas de Discriminação Contra a Mulher, de I979, entre outras.

Exemplificando, o Pacto Internacional dos Direitos Econômicos, Sociais e Culturais, de I966, reconhece o direito de toda a pessoa à educação e que a 
educação deverá visar ao pleno desenvolvimento da personalidade humana e do sentido de sua dignidade, fortalecendo o respeito pelos direitos humanos e pelas liberdades fundamentais (Art. I3, $\left.\int I^{\circ}\right)$.

\section{FIgURA 3}

TRAJETÓRIAS DA EA E DA EDS: DOCUMENTOS

INTERGOVERNAMENTAIS IMPORTANTES

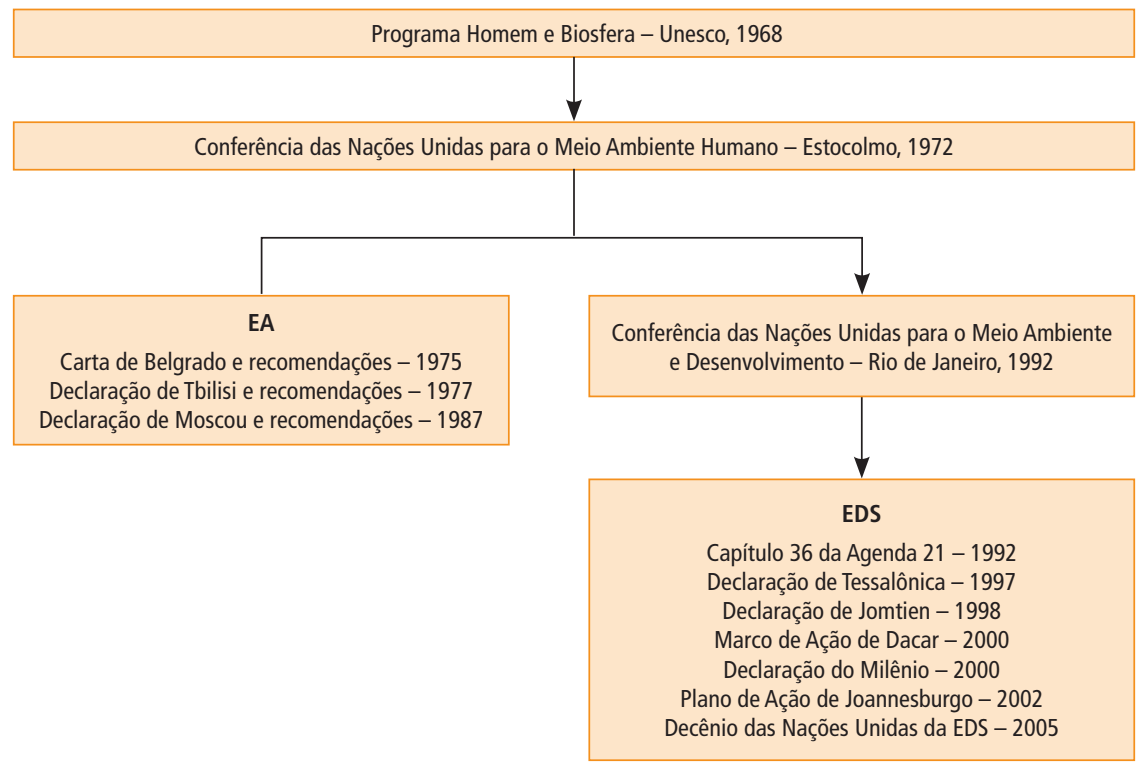

Fonte: Elaborada pelos autores.

A EA continuará a ter seu próprio campo e desenvolver-se-á de muitos modos, formando diversas correntes, como as apresentadas por Sauvé (2005). A EA, com base nos objetivos, nas diretrizes, nas recomendações e nos planos constantes nas conferências promovidas pela Unesco e pelo Pnuma, principalmente as de Belgrado e Tbilisi, continuará dando sua valiosa contribuição para o desenvolvimento sustentável, sem retirar a importância de outras concepções, como a de Joseph Cornell (I998), cujo objetivo básico é promover uma profunda interação do ser humano com a natureza, mediante atividades em grupo desenvolvidas ao ar livre. O foco dessa proposta é centrado no meio ambiente natural preservado ou conservado e tem como objetivo reconstruir uma ligação do ser humano com a natureza (CORNELL, I998).

Essa proposta não mostra preocupação com questões sociais como pobreza, equidade, entre outras, a não ser indiretamente. A diversidade de concepções de 
EA haverá sempre, pois decorre de diferentes entendimentos sobre a relação dos humanos com seu meio físico, biológico e social, de modo que respeitar essas concepções e dialogar com elas é uma postura coerente com o pluralismo tão enfatizado nos documentos fundadores do desenvolvimento sustentável, como Nosso futuro comum, a Agenda 2I e a Declaração sobre Meio Ambiente e Desenvolvimento do Rio de Janeiro.

\section{O PAPEL dAs INSTITUIÇões de ENSINO SUPERIOR}

Um aspecto importante da implantação da EA dentro dos objetivos, princípios e diretrizes do desenvolvimento se refere às contribuições das instituições de ensino superior (IES), para as quais foram feitas algumas recomendações que, em geral, não apresentam novidades. Por exemplo, o Seminário de Belgrado recomenda o desenvolvimento de programas de EA para alunos de nível superior em geral (Recomendação 5, letra f). Das recomendações de Tbilisi, uma se refere à necessidade de formação de profissionais específicos, como engenheiros, administradores, economistas e outros que exercem grande influência sobre o meio ambiente (Recomendação 8); e outra, à necessidade de criar programas pós-universitários para pessoas especializadas em alguma disciplina (Recomendação II).

A Agenda 2I recomenda que os países possam apoiar as universidades e outras atividades terciárias e redes para EA e o desenvolvimento, podendo estimular as relações de reciprocidade entre as universidades dos países desenvolvidos e em desenvolvimento (CONFERÊNCIA DAS NAÇÕES UNIDAS SOBRE MEIO AMBIENTE E DESENVOLVIMENTO, I992, seção 36.5). Note-se que, além de usar um verbo pobre em termos de comprometimento, podem apoiar e incentivar, ainda passa a ideia de que as contribuições das IES dependem de apoios externos. Por isso, as contribuições mais importantes e inovadoras vieram por iniciativa delas mesmas, como parte de um compromisso firme com o movimento pelo desenvolvimento sustentável, das quais resultaram declarações e recomendações específicas inovadoras.

Essas iniciativas são acordos voluntários que expressam um compromisso de atuar proativamente na busca pelo desenvolvimento sustentável. A lógica que preside esses acordos voluntários é ir além do que a legislação exige e liderar os processos de implantação de práticas alinhadas com esse novo modo de conceber o desenvolvimento.

A Declaração de Talloires é um dos mais importantes acordos voluntários específicos para as IES, tanto por sua anterioridade quanto pela influência que 
exerceu em outros acordos. Ela é constituída por dez macroações para as IES se engajarem ativamente na busca por esse novo modo de pensar o desenvolvimento e exercerem a liderança nesse processo.

A Declaração foi assinada em I990, em uma reunião realizada no campus da Universidade de Tufts, em Talloires, França, por vinte reitores, vice-reitores e outros mandatários de IES, entre eles o reitor da Unicamp, na época, professor Carlos Voigt. Atualmente, mais de 400 IES já subscreveram os termos dessa Declaração, incluindo 50 IES brasileiras, praticamente todas as universidades federais. É a iniciativa mais conhecida no Brasil, entre as IES mais comprometidas com o desenvolvimento sustentável.

Calder e Clugston (2003, p. 32) analisaram o movimento denominado Educação Superior para o Desenvolvimento Sustentável nos Estados Unidos e verificaram que também é mais popular entre as IES desse país.

A Declaração de Talloires não trata da EA diretamente nem a menciona de forma expressa, mas a inclui de modo indireto nas ações concernentes aos objetivos precípuos das IES voltadas para o alcance do desenvolvimento sustentável. Um exemplo disso é a ação para incentivar as universidades a se comprometer com educação, pesquisa, formulação de políticas e intercâmbios de informações de temas relacionados com população, meio ambiente e desenvolvimento, com o objetivo de alcançar um futuro sustentável (ação 3).

As adesões à Declaração são feitas por meio da Associação das Universidades Líderes para um Futuro Sustentável (University Leaders for a Sustainable Future - ULSF), que tem por objetivo apoiar o ensino, a pesquisa e as operações das universidades para que atuem de modo sustentável. A ULSF também exerce a função de secretaria das atividades decorrentes da Declaração de Talloires.

Outras iniciativas voluntárias surgiram seguindo o exemplo da Declaração de Talloires e inspiradas nela, como as citadas no Quadro I. Além dessas iniciativas de caráter geral, muitas outras foram elaboradas com objetivos e alcances regionais, como a Declaração de Haga, assinada em 2000 pelos ministros da Educação de diversos países, banhados pelo Mar Báltico; ou com objetivos e alcances setoriais, como a Declaração de Lucerna, de 2007, sobre Educação Geográfica para o Desenvolvimento Sustentável; e os Principles for Responsible Management Education (PRME), constituídos por seis princípios de ações voltados para o ensino de administração apresentados no Quadro 2.

Note que o princípio 2, relativo aos valores, menciona as iniciativas das Nações Unidas para reforçar o cumprimento dos princípios associados aos direitos humanos, ao trabalho e ao respeito ao meio ambiente nas práticas de gestão das organizações. 


\section{QUADRO I}

\section{PRINCIPAIS INICIATIVAS VOLUNTÁRIAS}

\section{DAS IES DE CARÁTER GERAL}

\begin{tabular}{|c|c|}
\hline DOCUMENTO & BREVE DESCRIÇÃO E HISTÓRICO/FONTES \\
\hline $\begin{array}{l}\text { Declaração } \\
\text { de Talloires } \\
\text { (França) }\end{array}$ & $\begin{array}{l}\text { Criada em 1990, é a primeira iniciativa voluntária de caráter geral. Ela deu } \\
\text { o tom para outras que vieram depois dela. Hoje, mais } 400 \text { IES subscreveram } \\
\text { seus termos (Disponível em: <http://www.ulsf.org/programs_talloires.html>. } \\
\text { Acesso em: } 7 \text { ago. 2009). }\end{array}$ \\
\hline $\begin{array}{l}\text { Declaração de } \\
\text { Halifax } \\
\text { (Canadá) }\end{array}$ & $\begin{array}{l}\text { Surge, em 1991, por iniciativa da Universidade das Nações Unidas e da } \\
\text { Associação de Universidades Canadenses, a declaração que contém seis } \\
\text { ações endereçadas às universidades. Além dela, foi elaborado um plano } \\
\text { de ação que procura fornecer um senso de direção claro para as diversas } \\
\text { atividades desenvolvidas pelas universidades, identificando-as como de } \\
\text { curto e longo prazos e de abrangência local, nacional e internacional. } \\
\text { Inclui também uma longa lista de recomendações nesses três níveis de } \\
\text { abrangência (Disponível em: <http://www.unesco.org/iau/sd/rtf/sd_dhalifax. } \\
\text { rtf>. Acesso em: } 7 \text { ago. 2009). }\end{array}$ \\
\hline $\begin{array}{l}\text { Declaração de } \\
\text { Swansea (País } \\
\text { de Gales) }\end{array}$ & $\begin{array}{l}\text { Criada em 1993, pela Associação das Universidades do Commonwealth, } \\
\text { também recebeu influência de Talloires, como a de Halifax. A Declaração } \\
\text { apresenta um conjunto de sete ações (Disponível em: <http://www.unesco. } \\
\text { org/iau/sd/rtf/sd_dswansea.rtf>. Acesso em: } 7 \text { ago. 2009). }\end{array}$ \\
\hline $\begin{array}{l}\text { Declaração de } \\
\text { Kyoto } \\
\text { (Japão) }\end{array}$ & $\begin{array}{l}\text { Criada em 1993, essa Declaração contém oito ações, e uma reconhece a } \\
\text { linguagem e as mesmas questões de Halifax e Swansea (Disponível em: } \\
<\text { http://www.unesco.org/iau/sd/sd_dkyoto.html>. Acesso em: } 7 \text { ago. } 2009 .\end{array}$ \\
\hline $\begin{array}{c}\text { Carta } \\
\text { Copernicus }\end{array}$ & $\begin{array}{l}\text { Assinada em } 1994 \text { em Genebra, a Carta Copernicus (CO-operation } \\
\text { Programme in Europe for Research on Nature and Industry through } \\
\text { Coordinated University Studies) é um desdobramento do programa europeu } \\
\text { de cooperação entre universidades. Define o papel das universidades e } \\
\text { instituições de ensino superior na busca pelo desenvolvimento sustentável } \\
\text { e apresenta princípios de ação, como comprometimento institucional } \\
\text { com o desenvolvimento sustentável, ética ambiental, educação para } \\
\text { os funcionários, programas de EA, interdisciplinaridade, difusão de } \\
\text { conhecimentos, atuação em redes, parcerias, transferência de tecnologia e } \\
\text { programas de educação continuada (Disponível em: <www.eso.ed.ac.uk/ } \\
\text { pdfs/CopernicusUpdate2000.pdf>. Acesso em: } 7 \text { ago. 2009). }\end{array}$ \\
\hline
\end{tabular}




\section{QUADRO I (CONCLUSÃO)}

\section{PRINCIPAIS INICIATIVAS VOLUNTÁRIAS}

DAS IES DE CARÁTER GERAL

\begin{tabular}{|c|c|}
\hline DOCUMENTO & BREVE DESCRIÇÃO E HISTÓRICO/FONTES \\
\hline $\begin{array}{c}\text { Declaração de } \\
\text { Lüneburg } \\
\text { (Alemanha) }\end{array}$ & $\begin{array}{l}\text { Declaração de Lüneburg sobre educação superior para o desenvolvimento } \\
\text { sustentável. Assinada em 2001, afirma a necessidade de implantar } \\
\text { as recomendações do Capítulo } 36 \text { da Agenda 21, da Declaração de } \\
\text { Tessalônica e outras. Foi elaborada em reunião preparatória para a Cúpula } \\
\text { Mundial para o Desenvolvimento Sustentável de 2002, em Johannesburgo } \\
\text { (Rio + 10) (Disponível em: <www.unesco.org/iau/sd/rtf/sd_dluneburg.rtf>. } \\
\text { Acesso em: } 7 \text { ago. 2009). }\end{array}$ \\
\hline $\begin{array}{c}\text { Declaração de } \\
\text { Ubuntu }\end{array}$ & $\begin{array}{l}\text { Declaração de Ubunto sobre educação, ciência e tecnologia para o } \\
\text { desenvolvimento sustentável. Foi elaborada durante a Cúpula Mundial para } \\
\text { o Desenvolvimento Sustentável e apoiada pela Universidade das Nações } \\
\text { Unidas, Unesco, ULSF, Academia de Ciência da África, Campus-Copernicus } \\
\text { etc. Reforça a necessidade de atender às recomendações da Agenda } 21 \text { e } \\
\text { da Carta da Terra, documento independente que começou a ser elaborado } \\
\text { na Cmmad no Rio de Janeiro em } 1992 \text { e foi concluído em } 2000 \text { (Disponível } \\
\text { em: <www.deat.gov.za/sustdev/documents/pdf/UbuntuDeclaration.pdf>. } \\
\text { Acesso em: } 7 \text { ago. 2009). }\end{array}$ \\
\hline
\end{tabular}

Fonte: Síntese das páginas das iniciativas acessadas na web citadas em cada linha.

\section{QUADRO 2}

PRINCÍPIOS PARA A EDUCAÇÃO DE GESTÃO RESPONSÁVEL (PRINCIPLES FOR RESPONSIBLE MANAGEMENT EDUCATION - PRME)

\begin{tabular}{cl}
\hline PRINCÍPIO & ENUNCIADO \\
\hline $\begin{array}{c}\text { Propósito } \\
\text { e para lutar por uma economia global inclusiva e sustentável. }\end{array}$ & $\begin{array}{l}\text { geradores de valores sustentáveis para os negócios e a sociedade como um } \\
\text { Incorporaremos, em nossas atividades acadêmicas e curriculares, os valore }\end{array}$ \\
\hline 2 & $\begin{array}{l}\text { de responsabilidade social global, conforme considerado em iniciativas } \\
\text { internacionais, como o Pacto Global das Nações Unidas. }\end{array}$ \\
\hline 3 & $\begin{array}{l}\text { Criaremos estruturas educacionais, materiais, processos e condições que } \\
\text { permitam realizar experiências de aprendizagem eficazes para a liderança } \\
\text { Método }\end{array}$ \\
\end{tabular}




\section{QUADRO 2 (CONCLUSÃO)}

PRINCÍPIOS PARA A EDUCAÇÃO DE GESTÃO RESPONSÁVEL

(PRINCIPLES FOR RESPONSIBLE MANAGEMENT

EDUCATION - PRME)

\begin{tabular}{cl}
\hline PRINCÍPIOO & ENUNCIADO \\
\hline 4 & $\begin{array}{l}\text { Engajar-nos-emos em pesquisas conceituais e empíricas que aumentem nosso } \\
\text { entendimento sobre o papel e os impactos das empresas na criação de valor } \\
\text { social, ambiental e econômico sustentável. }\end{array}$ \\
\hline 5 & $\begin{array}{l}\text { Interagiremos com gestores de empresas para estender nosso conhecimento } \\
\text { sobre seus desafios concernentes à junção das responsabilidades sociais e } \\
\text { ambientais e para explorar conjuntamente abordagens eficazes para responder a } \\
\text { esses desafios. }\end{array}$ \\
\hline $\begin{array}{l}\text { Facilitaremos e apoiaremos o diálogo e o debate entre educadores, empresas, } \\
\text { consumidores, mídia, organizações da sociedade civil e outros grupos de } \\
\text { interesse e partes interessadas sobre questões críticas sobre responsabilidade } \\
\text { social e sustentabilidade global. } \\
\text { Entendemos que nossas próprias práticas organizacionais devem servir como } \\
\text { exemplo dos valores e das atitudes que transmitimos aos nossos alunos. }\end{array}$ \\
\hline
\end{tabular}

Fonte: Os seis princípios podem ser consultados em Responsible Management Education.

Disponível em: <www.unprme.org>. Acesso em: 7 ago. 2009.

Essas iniciativas voluntárias não são específicas para a EA. Elas visam colocar as IES como parceiras privilegiadas do desenvolvimento sustentável de modo explícito. Elas facilitam a inserção das IES no movimento do desenvolvimento sustentável, pois favorecem o aprendizado entre as signatárias de um mesmo acordo. Mas não é o único caminho. Uma IES pode criar uma agenda 2I própria que contemple programas, projetos e atividades de todo o tipo (ensino, pesquisa, extensão, gestão, difusão de conhecimento, participação em conselhos municipais etc.) e que envolvam professores, alunos, funcionários, fornecedores e prestadores de serviço, comunidade do entorno, ONGs, poder público local, estadual, nacional, entre outros grupos.

\section{CONSIDERAÇÕES FINAIS}

O objetivo deste artigo foi apresentar a gênese de uma concepção de EA associada ao movimento do desenvolvimento sustentável e um debate importante que surgiu ao longo de sua trajetória, com a proposta de educação para o 
desenvolvimento sustentável (EDS). Para tal, foram resgatados aspectos históricos e conceituais dos movimentos observados no mundo desde a criação da Unesco. Assim, diante do exposto, pode-se pensar em algumas considerações que visem dar sentindo e permitir incorporar a EA nos cursos de Administração e em outros de nível superior, considerando que a legislação nacional sobre essa matéria foi profundamente influenciada pelos documentos intergovernamentais mencionados, além dos que foram produzidos aqui, como a Declaração de Brasília, de I997 (BRASIL, I997).

Um dos aspectos a ser destacado é que a EA deve ser implantada por meio de uma abordagem interdisciplinar, como diz a Carta de Belgrado, ou abordagens multidisciplinar, interdisciplinar e transdisciplinar, como estabelece a Política Nacional de Educação Ambiental (BRASIL, I999, art. $4^{\circ}$ ).

Entende-se que a EA não deve implantada como disciplina específica (BRASIL, I999, art. I0 ${ }^{\circ}$ ), mas incluída em todas as oportunidades de ensino, como um processo contínuo que deve se estender para fora das instalações escolares, de modo a considerar o meio ambiente em suas múltiplas dimensões. Esse desiderato não se realiza sem que os docentes sejam capazes de tratar as questões ambientais inter-relacionadas com os temas das disciplinas que ministram, o que pressupõe formação em EA. Por isso, disciplinas específicas de EA só se justificam nos cursos de pós-graduação (BRASIL, I999, art. I0), por onde deverão passar os futuros docentes.

Como esse processo é lento e as questões ambientais requerem urgência, a adesão a uma iniciativa voluntária criada pelas instituições de ensino e pesquisa, dentre as muitas existentes, algumas aqui citadas, é um meio para apressar o aprendizado com base na cooperação entre as participantes da iniciativa.

Outra questão que merece comentário é a relação da EA com as disciplinas de gestão ambiental, cada vez mais frequentes nos cursos de graduação em Administração. Elas tratam de conteúdos de formação profissional, pois estão relacionadas com áreas específicas, embora não sejam citadas em resoluções do MEC, a exemplo de marketing, produção, logística, finanças etc. (BRASIL, 2005).

A gestão ambiental está voltada para a aplicação de conhecimentos teóricos e práticos aos problemas ambientais que concernem às organizações, por meio de processos administrativos típicos, como planejamento, controle, coordenação, motivação e outros, para alcançar objetivos e metas específicos em diferentes níveis de atuação, do operacional ao estratégico.

Os objetivos da EA são mais amplos, como mostrado no início deste texto, porém EA e EDS podem se articular e se reforçar mutuamente, desde que se tornem compatíveis. Para isso, a gestão ambiental deve estar afinada com o movimento do desenvolvimento sustentável, uma vez que a EA acolhida pela legisla- 
ção pátria foi gestada nesse movimento. O aprendizado em gestão ambiental se torna mais efetivo quando os alunos estão sensibilizados e conscientes acerca do meio ambiente e dos problemas decorrentes das ações humanas.

\section{SUSTAINABLE DEVELOPMENT AND ENVIRONMENTAL EDUCATION: A COMMON TREND WITH MANY CHALLENGES}

\section{ABSTRACT}

The purpose of this paper is to present the emergence of a conception of environmental education (EE) associated with the movement of sustainable development and a proposal for education for sustainable development (ESD) in view of its application in Business Administration, for as will be shown in its design gave particular attention to the professionals whose activities and decisions have significant repercussions on the environment, such as administrators, economists, engineers, architects, product developers, policy makers, among others. It will present the main intergovernmental events that gave rise to this conception of EE, the main guidelines and recommendations applied to these professionals and a proposal for EDS and its relationship with EE. Afterward, it will present a discussion about EE and ESD, because there are diametrically opposed understandings about these two conceptions of education. Distinct aspects of the concept of sustainable development and the controversial issues that generate doubts and objections about it will also be presented, in order to clarify myths and avoid naive conceptions. It will address issues related to economic growth, one of the main questions concerning the concept of sustainable development. This article discusses the concepts and recommendations contained in intergovernmental documents, especially those created by agencies of $U N$, that established milestones for the debate and introduced elements that initiated global EE actions. Finally, it presents some of the main voluntary initiatives for the integration of Higher Education Institutions, just as Talloires Declaration, in the movement of sustainable development, to implement the EE and ESD.

\section{KEYWORDS}

Environmental education; Education for sustainability; Sustainable development; Environmental; Business administration education. 


\section{DESARROLLO SOSTENIBLE Y LA EDUCACIÓN AMBIENTAL: UNA TENDENCIA COMÚN CON MUCHOS DESAFÍOS}

\section{RESUMEN}

El propósito de este trabajo es presentar el surgimiento de una concepción de la educación ambiental (EA) asociada con el movimiento del desarrollo sostenible y una propuesta de educación para el desarrollo sostenible (EDS), teniendo en cuenta los cursos en Administración de Empresas, pues, como se mostrará, en su diseño se prestó especial atención a los profesionales cuyas actividades y decisiones tienen repercusiones significativas sobre el medio ambiente, tales como administradores, economistas, ingenieros, arquitectos, desarrolladores de productos, responsables políticos, entre otros. Presentará los principales eventos intergubernamentales que dieron origen a esta concepción de la EA, las principales directrices y recomendaciones que se aplican a estos profesionales y una propuesta de EDS y su relación con EA. Después, será presentado un debate sobre la EA e la EDS, pues hay comprensiones diametralmente opuestas acerca de estas dos concepciones de la educación. También se presentará distintas comprensiones del concepto de desarrollo sostenible y las cuestiones controvertidas que generan dudas y objeciones a su respecto con el objetivo de aclarar mitos y concepciones ingenuas. Además, se abordarán cuestiones relacionadas con el crecimiento económico y su relación con el desarrollo, una de las principales cuestiones controvertidas a respecto del desarrollo sostenible. El artículo discutirá conceptos y recomendaciones presentes en los documentos intergubernamentales, especialmente los producidos por las agencias de la ONU, que establecieron las bases para el debate y introdujeron elementos que desataron acciones mundiales de EA. Por último se presentan algunas de las iniciativas voluntarias más importantes para la integración de las Instituciones de Educación Superior, como la Declaración de Talloires, en el movimiento del desarrollo sostenible, para aplicar la EA y la EDS.

\section{PALABRAS CLAVE}

Educación ambiental; Educación para la sostenibilidad; Desarrollo sostenible; Medio ambiente; Enseñanza de Administración. 


\section{REFERÊNCIAS}

ABBAGNANO, N. Dicionário de filosofia. São Paulo: Martins Fontes, 2007.

ASAMBLEA GENERAL DE LAS NACIONES UNIDAS. Conferencia internacional sobre medio ambiente y sociedad: educación y sensibilización para la sostenibilidad (Declaración de Salónica). Salónica: ONU, I997. Disponível em: <http://www.jmarcano.com/educa/docs/salonica.html>. Acesso em: 30 abr. 2010.

ASAMBLEA GENERAL DE LAS NACIONES UNIDAS. Resolución 57/254. In: SESIÓN PLENARIA, 78. Decenio de las Naciones Unidas de la Educación para el desarrollo sostenible. Asamblea General, 20 de enero de 2002. New York: ONU/Sesión Plenaria, 2002.

ASSEMBLÉIA GERAL DAS NAÇÕES UNIDAS. Pacto internacional dos direitos econômicos, sócias e culturais. Resolução 2.200-A, Ig66. Ratificado pelo Brasil em 24 jan. I992.

BRASIL. Ministério do Meio Ambiente. Declaração de Brasília. I997. Disponível em: <http://www. mma.gov.br/port/sdi/ea/Infgeral.cfm>. Acesso em: 9 dez. 2000.

Lei n. 9.795, de 27 de abril de I999. Institui a Política Nacional de Educação Ambiental. Diário Oficial da União, Brasília, seção I, p. I-4, abr. I999.

Ministério da Educação/Conselho Nacional de Educação/Câmara de Educação Superior. Resolução n. 4, de I3 de julho de 2005. Institui as diretrizes curriculares nacionais do curso de administração, bacharelado e dá outras providências. Diário Oficial da União, Brasília, seção I, p. 26-27, i9 jul. 2005 .

. Órgão Gestor da Política Nacional de Educação Ambiental (OG-PNEA). Mapeamento da educação ambiental em instituições brasileiras de educação superior: elementos para políticas públicas. OG-ProNEA. Documentos Técnicos - I2, 2007. Disponível em: <http://www.mma.gov.br/ estruturas/educamb/_arquivos/dt_I2.pdf>. Acesso em: 20 ago. 2010.

CALDER, W.; CLUGSTON, R. M. Progress toward sustainability in higher education. Environmental law institute: news \& analysis. Washington, DC: Environmental Law Institute, 2003.

CALDWELL, L. K. Ecologia: ciência y política medioambiental. Madrid: McGraw-Hill, I993.

CNUMAH. Declaração de Estocolmo sobre o ambiente humano. Estocolomo, I972. Disponível em: <http://www.educacaoambiental.pro.br/victor/unidades/DeclaraAmbienteHumano.pdf>.

Acesso em: I2 maio 2010.

COMISSÃO MUNDIAL SOBRE MEIO AMBIENTE E DESENVOLVIMENTO (CMMAD). Nosso futuro comum. Rio de Janeiro: Fundação Getulio Vargas, I99I.

COMISIÓN SOBRE DESARROLLO SOSTENIBLE (CDS). Progreso general alcanzado desde la celebración de la Conferencia de las Naciones Unidas sobre el Medio Ambiente y el Desarrollo: informe del secretario general. New York: ONU/CDS, E/CN.I7/I997/2/Add.26, I997.

CONFERÊNCIA DAS NAÇÕES UNIDAS SOBRE MEIO AMBIENTE E DESENVOLVIMENTO

(CNUMAD). Agenda 21. São Paulo: Secretaria de Estado do Meio Ambiente, I992.

CORNELL, J. B. A sharing nature with children. 2. ed. Nevada City: Dawn Publication, I998.

CUMBRE MUNDIAL SOBRE DESARROLLO SOSTENIBLE (CMDS). Plan de acción de la Cumbre Mundial sobre Desarrollo Sostenible. New York: ONU/CMDS, 2002.

DALY, H. E. A economia ecológica e o desenvolvimento sustentável. Tradução John Cunha Comerfort. Rio de Janeiro: Assessoria e Serviços a Projetos em Agricultura Alternativa, I99I. Textos para debates. 
ELKINGTON, J. Cannibals with forks: the triple botton line of 2Ist century business. Oxford: Capstone, 2000.

HASSELINK, F.; KEMPEN, P. P. van; WALS, A. International debate on education for sustainable development (ESDebate). Gland, Switzerland: IUCN, CEC, 2000. Disponível em: <http://www. iucn.org>. Acesso em: 2I mar. 2005.

HOLLAND, A. Sustainability. In: JAMIESON, D. (Org.). A companion to environmental philosophy. London: Blackwell, 2003.

HOPKINS, C.; MCKEOWN, R. Education for sustainable development: an international perspective. In: TILBURY, D. et al. Education and sustainability: responding to the global challenge. Gland, Switzerland: IUCN, CEC, 2002.

LÉLÉ, S. M. Sustainable development: a critical review. World Development, Montreal, v. I9, n. 6, p. 607-62I, June I99I.

MCKEOWN, R. Manual de educación para el desarrollo sostenible. Universidade do Tennessee: Centro de Energia, Medio Ambiente y Recursos, 2002. Disponível em: <http://www.edstoolkit.org>. Acesso em: 27 mar. 2009 .

MCNEILL, J. Something new under the sun: an environmental history of the twentieth century. London: Penguin Books, 2000.

O'RIORDAN, T. Democracy and the sustainability transition. In: LAFFERTY, W. M.; MEADOWCROFT, J. (Org.). Democracy and the envieroment: problems and prospects. Cheltenham: Edward Elgar, I997.

PEDRINI, A. G. Educação ambiental para o desenvolvimento sustentável ou sociedade sustentável? Uma breve reflexão para a América Latina. Revista (virtual) Educação Ambiental em Ação, Novo Hamburgo, v. 5, n. I7, jun./ago. 2006.

PORRIT, J. Actuar con prudência: ciencia y medio ambiente. Barcelona: Blume, 2003.

SACHS, I. Estratégias de transição para o século XXI: desenvolvimento e meio ambiente. São Paulo: Studio Nobel, Fundação de Desenvolvimento Administrativo, I993.

SAUVÉ, L. Currents in environmental education: mapping a complex and evolving pedagogical field. Canadian Journal of Environmental Education, Ontario, v. IO, n. I, p. II-37, Spring 2005.

SAVITZ, A. W.; WEBER, K. The triple bottom line: how today's best-run companies are achieving economic, social and environmental success and how you can too. San Francisco: John Willey \& Sons, 2006.

UNESCO. Declaração Mundial sobre Educação para Todos (Conferência de Jomtien). Tailândia: Unesco, I990. Disponível em: <http://www.unesco.org.br/publicação/doc-inernacionais>. Acesso em: 20 set. 2010.

UNESCO. Educación para um futuro sostenible: una visión transdisciplinaria para una acción concertada. Paris: Unesco, EPD-97/CONF.401/CLD.I, I997.

VILLENEUVE, C. Qui a peur de l'an 2000?: guide d'education relative à l'environnement pour le développement durable. Paris: UNESCO, I998.

WORLD BANK. World development report, 1992. New York: World Bank and Oxford University Press, I992. 